\title{
Homo-dimerization and ligand binding by the leucine-rich repeat domain at RHG1/RFS2 underlying resistance to two soybean pathogens
}

Ahmed J Afzal ${ }^{1,2}$, Ali Srour ${ }^{1,2}$, Abhishek Goil ${ }^{1,2}$, Sheeja Vasudaven ${ }^{1,3}$, Tianyun Liư ${ }^{4}$, Ram Samudrala ${ }^{4}$, Navneet Dogra ${ }^{5}$, Punit Kohli ${ }^{5}$, Ayan Malakar ${ }^{1,2}$ and David A Lightfoot ${ }^{1,2^{*}}$

\begin{abstract}
Background: The protein encoded by GmRLK18-1 (Glyma_18_02680 on chromosome 18) was a receptor like kinase (RLK) encoded within the soybean (Glycine max L. Merr.) Rhg1/Rfs2 locus. The locus underlies resistance to the soybean cyst nematode (SCN) Heterodera glycines (I.) and causal agent of sudden death syndrome (SDS) Fusarium virguliforme (Aoki). Previously the leucine rich repeat (LRR) domain was expressed in Escherichia coli.

Results: The aims here were to evaluate the LRRs ability to; homo-dimerize; bind larger proteins; and bind to small peptides. Western analysis suggested homo-dimers could form after protein extraction from roots. The purified LRR domain, from residue 131-485, was seen to form a mixture of monomers and homo-dimers in vitro. Cross-linking experiments in vitro showed the $\mathrm{H} 274 \mathrm{~N}$ region was close $(<11.1 \mathrm{~A})$ to the highly conserved cysteine residue $\mathrm{C} 196$ on the second homo-dimer subunit. Binding constants of 20-142 nM for peptides found in plant and nematode secretions were found. Effects on plant phenotypes including wilting, stem bending and resistance to infection by SCN were observed when roots were treated with $50 \mathrm{pM}$ of the peptides. Far-Western analyses followed by MS showed methionine synthase and cyclophilin bound strongly to the LRR domain. A second LRR from GmRLK08-1 (Glyma_08_g11350) did not show these strong interactions.

Conclusions: The LRR domain of the GmRLK18-1 protein formed both a monomer and a homo-dimer. The LRR domain bound avidly to 4 different CLE peptides, a cyclophilin and a methionine synthase. The CLE peptides GmTGIF, GmCLE34, GmCLE3 and HgCLE were previously reported to be involved in root growth inhibition but here GmTGIF and HgCLE were shown to alter stem morphology and resistance to SCN. One of several models from homology and ab-initio modeling was partially validated by cross-linking. The effect of the 3 amino acid replacements present among RLK allotypes, A87V, Q115K and H274N were predicted to alter domain stability and function. Therefore, the LRR domain of GmRLK18-1 might underlie both root development and disease resistance in soybean and provide an avenue to develop new variants and ligands that might promote reduced losses to SCN.
\end{abstract}

Keywords: Receptor, Leucine-rich repeat, Ligand, Peptide, Cross-link, Predicted

\footnotetext{
* Correspondence: ga4082@siu.edu

'Department of Molecular Biology, Microbiology and Biochemistry and

Center for Excellence the Illinois Soybean Center, Southern Illinois University at Carbondale, IL 62901, USA

${ }^{2}$ Genomics Core Facility; Department of Plant Soil and Agricultural Systems,

Southern Illinois University at Carbondale, Carbondale, IL 62901-4415, USA

Full list of author information is available at the end of the article
} 


\section{Background}

Plants employ both cell surface and cytoplasmic receptors to respond to a wide array of signals from pathogens [1]. The receptor protein kinases (RPKs) represent one of the two large gene families implicated to underlie the recognition events that lead to pathogen resistance [2]. Two of the most destructive pathogens in soybean (Glycine max L. Merr.) are the soybean cyst nematode (SCN; Heterodera glycines I.) and sudden death syndrome (SDS) agent Fusarium virguliforme (Aoki) [3]. The complex genetics of the cyst nematode populations, the partial nature of plant resistance and temperature sensitivity makes controlling the nematode a difficult task $[4,5]$. Elicitation of plant defenses in response to the pathogens were shown to involve the activity of RLK proteins [5-8] introgressed from Peking. Two loci, Rhg4 on chromosome 8 (linkage group (Lg) A2) and Rhg1/Rfs 2 on chromosome 18 ( $\operatorname{Lg} \mathrm{G})$, contain genes that encode receptor like kinase (RLK) proteins within the RPK gene family implicated in resistance. GmRLK08-1 (Glyma_08_11350) is near Rhg4 and GmRLK18-1 (Glyma_18_02680) is within Rhg1/ $R f s 2$ [5,8-10]. The translated proteins are both RLKs with extra-cellular leucine rich repeats (LRR). Many other genes can alter SCN responses. However, only GmRLK18-1 has been shown to underlie resistance to both pathogens in transgenic plants $[8,9]$

Numerous studies have implicated the LRR domain of RLKs in effector recognition and protein-protein interactions [1,2,5,11-19]. The intracellular kinase domains of RLKs are often involved in phosphorylation mediated signal transduction. The GmRLK18-1 protein shows separated domains of different function that are a characteristic feature of both plant and animal RLKs. The extracellular domains are predicted to be involved in dimerization/recognition and the intracellular domain is involved in signal transduction. The GmRLK18-1 protein was predicted to be an 855 amino acid polypeptide that encoded an Nterminal signal peptide (amino acids 1-61), 10 extracellular leucine rich repeats (amino acids 141-471), a single pass trans-membrane domain (amino acids 485-507), and an intracellular serine/threonine kinase domain (amino acids 510-855; 5).

At $R h g 1 / R f s 2$, the resistance phenotypes were perfectly associated with the GmRLK18-1 allotype 1 [5] and that allele in transgenic plants provided partial resistance [8]. Combined, the amino acid changes (A87V, Q115K and $\mathrm{H} 274 \mathrm{~N}$ ) were sufficient to differentiate between plant introductions possessing type I resistance (Peking based resistance) and four other allotypes. No studies to date have attempted to analyze the role of these amino acid changes on overall protein structure, hence the molecular basis of resistance to SCN and SDS pathogenesis remains unexplored.

A recent study [6] shed light on secondary structural components of the GmRLK18-1 LRR domain. Helix and sheet content coincided with an alpha beta structural fold. Some unstructured elements within the LRR domain were inferred through circular dichroism (CD) spectrometry. Allotype comparisons were not yet made due to inherent refolding problems associated with some LRR proteins. In many instances, protein structure can be predicted by comparison to homologs of known structure [20-23]. For the GmRLK18-1 LRR-domain residues 141-435 expressed in E. coli [6] the nearest orthologs, judged by primary sequence similarity and length, with known structures included; 1ogq_a (PGIP) [16], 3rgx (BRI1) [18,19], 1xcd_a (decorin) [21], 1o6s (E-cadherin) [15]; 1ozn_a (NOGO receptor, ligand binding domain) [22]; and $2 \mathrm{bnh}$ (porcine ribonuclease inhibitor; PRI) [23].

Disregarding the length of the LRR domain, the polygalacturonase-inhibiting protein from Phaseolus vulgaris (PGIP) [16] was the closest ortholog of GmRLK18-1 with a known structure, sharing 27 percent identity and 44 percent similarity (http://www.sbg.bio.ic.ac.uk/ $\sim$ phyre2/html/page.cgi?id=index). Next was the BRI1 receptor $[18,19]$ that was $27 \%$ identical and $42 \%$ similar in the LRR region (residues 141-435). The PRI protein [23] shared $20 \%$ identity and $36 \%$ similarity with the GmRLK18-1-LRR, was of similar length and was known to form homo-dimers in vivo. Among well studied plant RLK-R proteins the LRR of GmRLK18-1 was most similar (39\%) to the rice XA21 receptor kinase LRR [11,24]. XA21 is a RLK, the extra-cellular domain of which controls race specific pathogen recognition in response to a known elicitor. The binding of the pathogen ligand to the XA21 LRR-domain may result in dimerization and activation of intracellular kinase. Among genes involved in the control of development the GmRLK18-1 LRR domain was $43 \%$ similar to Arabidopsis CLAVATA1 and CLAVATA2 that heterodimerize [25]. The GmRLK18-1 LRR domain was $45 \%$ similar to soybean NARK1 [26]. These latter 3 proteins have been shown to bind CLE peptides as part of their activity. There is a CLE peptide in nematode secretions that was shown to be perceived by RLKs in the CLAVATA2 and CORYNE families [25] raising the possibility that GmRLK18-1 might bind CLE peptides. Binding constants $(\mathrm{Kd})$ for CLE peptides were reported in the range of 17.4-2,000 $\mathrm{nM}$.

Previously a three dimensional model for an RPK protein [27] was predicted but the modeled RPK protein was not an RLK. Equally, a model for and RLK was predicted, but the protein acted in symbiosis not defense [26]. Here a model of the LRR domain from a RLK protein involved in resistance is reported based on homology modeling of the extracellular LRR domain (residue 141-471) of the GmRLK18-1 protein. Modeling for GmRLK18-1-LRR was based on PRI (2BNH) [23]. The effect of the amino acid substitutions on protein stability 
was inferred; structure for fold and class analysis was made; and secondary structure was analyzed in vitro and in silico to predict whether GmRLK18-1 may homodimerize in vivo. The models were tested with proteins cross linked in vitro. Ligand binding was measured with short CLE-like peptides.

\section{Results}

\section{Analyses of protein sequences}

The GmRLK18-1-LRR domain showed diverged motifs but in a regularly repeating pattern (Figure 1) [2]. Conversely, the kinase domain contained the expected conserved motifs and therefore appeared to have experienced purifying selection. The synonymous and non-synonymous substitution rates in both these domains differed as well (Figure 1). Eight of the nine known alleles of the RLK at the rhg1 locus [5] were aligned using CLUSTAL-W and rates of synonymous and non-synonymous substitutions determined. The ratio of non-synonymous to synonymous substitutions in the LRR-domain was observed to be about 1:1 whereas in the kinase domain, most nucleotide substitutions did not translate into amino acid changes and the ratio exceeded 3:1. The ratios suggest purifying selection eliminated mutants in the kinase domain but not the LRR domain. The relative lack of amino acid sequence variance per nucleotide change may be associated with the role of the kinase domain in the signaling function. Appropriate message transduction imposes severe constraints on amino acid substitutions. In contrast, the LRR-domains may be expected to accumulate mutations that are neutral, improve the current function or lead to new adaptive recognition capabilities.

\section{Detection of homo-dimers for GmRLK18-1 but not GmRLK08-1}

The LRR domains of GmRLK18-1 and GmRLK08-1 were expressed in $E$. coli by the same methods. Native page gels consistently showed 2 bands of $38.4 \mathrm{Kd}$ and 76.8Kd for GmRLK18-1 (Figure 2A) but only a single bands at 38.1 Kd for GmRLK08-1 (data not shown). The $76.8 \mathrm{Kd}$ bands could be eluted and electrophoresed on SDS-PAGE where the apparent size was halved to 38.4 Kd by denaturation. Proteins extracted from plant roots and subject to non-denaturing PAGE and Western

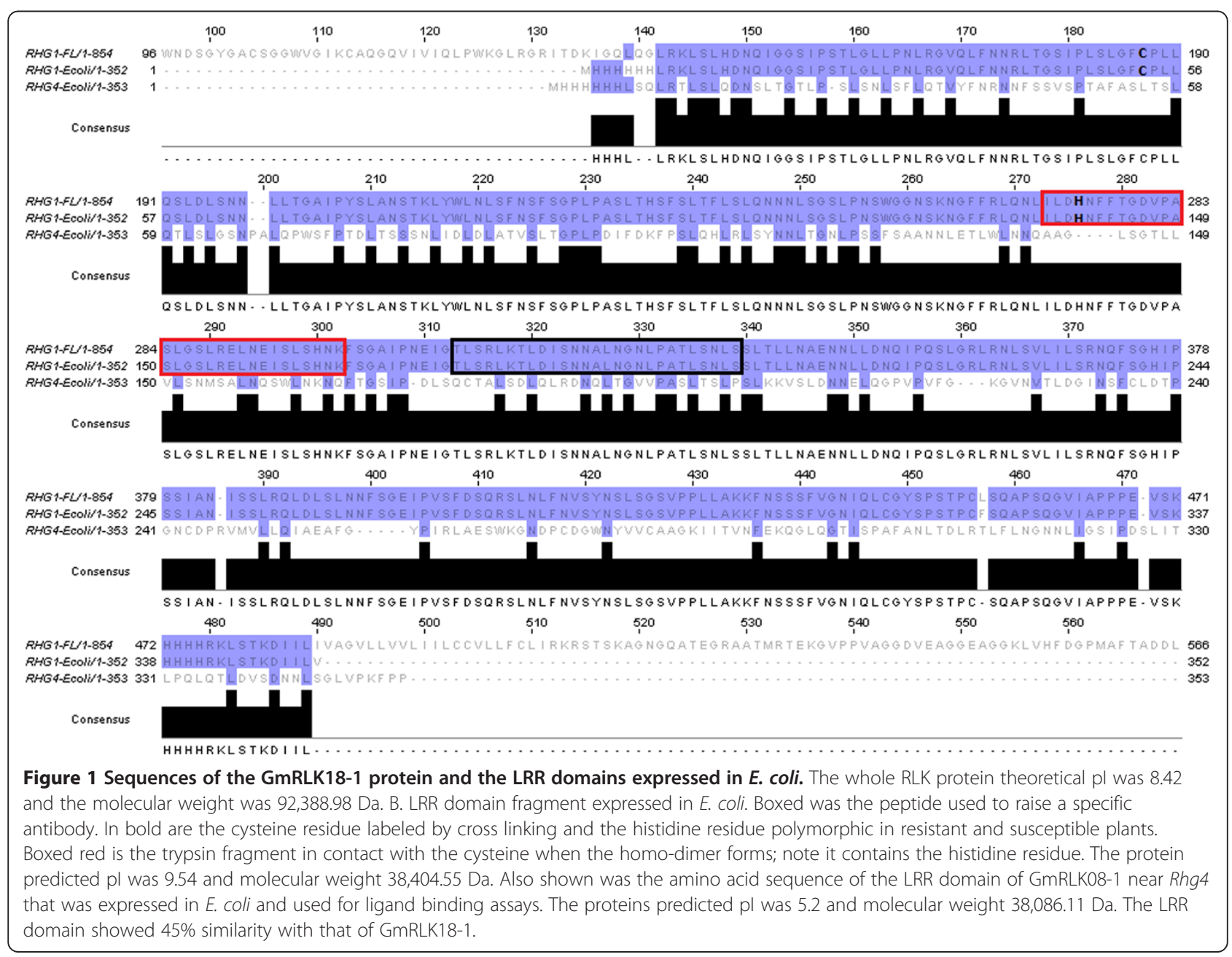




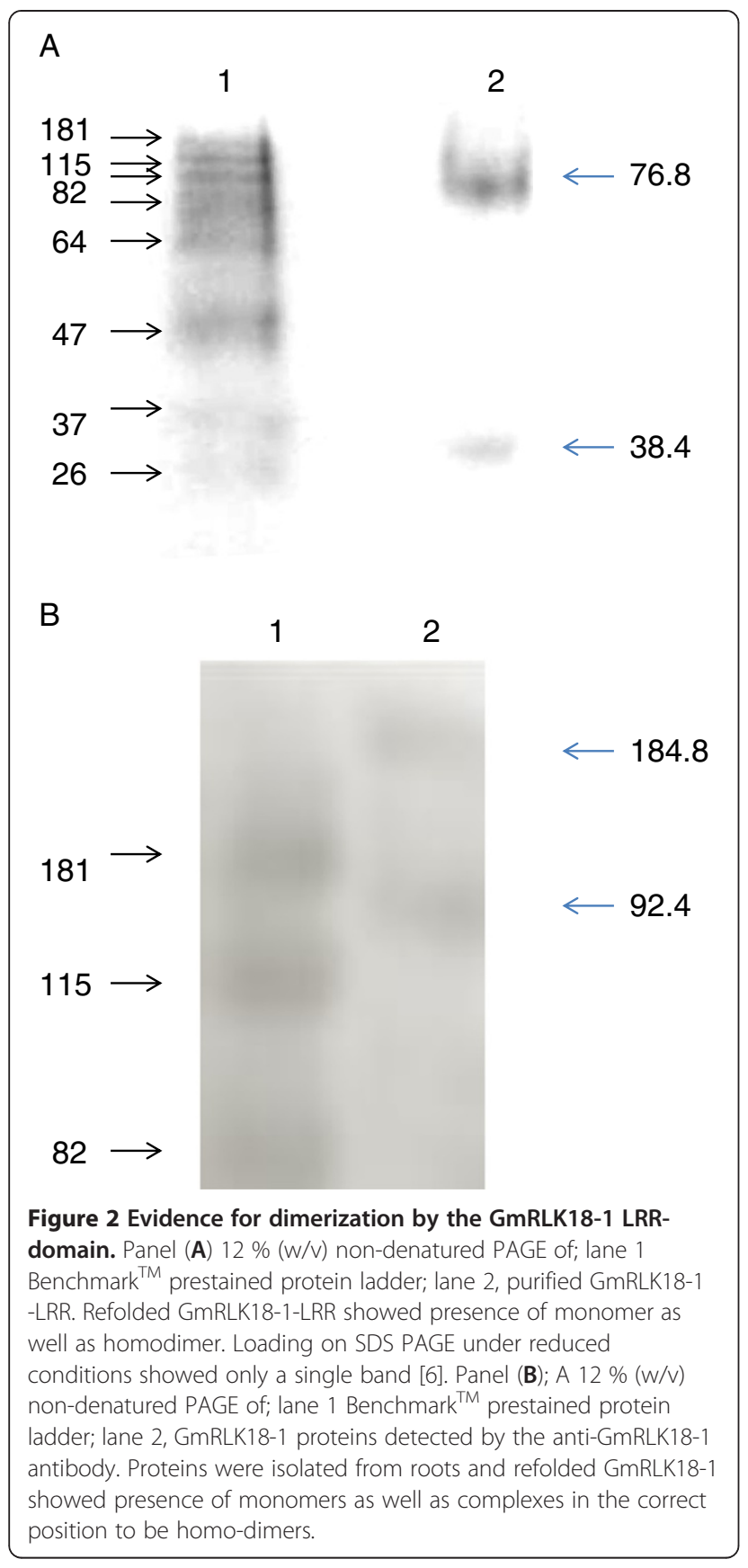

transfer also appeared capable of maintaining homodimers and/or forming a hetero-dimers with another protein of similar mass and charge (Figure $2 \mathrm{~B}$ ). The predicted monomer band at $92.4 \mathrm{Kd}$ electrophoresed more slowly than expected relative to the globular marker proteins as did the predicted homo-dimer $184.8 \mathrm{Kd}$ band. Non-denaturing electrophoresis of proteins provides inaccurate estimates of size based on size and charge density. In this case the very low abundance RLK was a refolded protein following solubilization from the membrane bound fraction. Possibly the exposed trans- membrane domain or other unstructured elements reduced the rate of the proteins migration.

\section{Cross-linking between homodimers in GmRLK18-1 but not GmRLK08-1}

From cross-linking with MTBS it was found that within $11 \mathrm{~A}^{\mathrm{O}}$ from $\mathrm{C} 57$ to adjacent amino acids two sets of ion signals were observed which may both be assigned to the same region of a homodimer. The two biotinylated, trypsin digest derived, peptides that resulted from crosslinking started from residue 136 and ended with residue 169 (high abundance signal, mass 3791.97, 1 missed cleavage) and started with residue 131 and ended with residue 169 (low abundance signal, mass 4413.27, 2 missed cleavages). This means that C57 in the LRR or $\mathrm{C} 215$ in the whole protein are adjacent $(>11 \mathrm{~A})$ to the region containing the $\mathrm{H} 274 \mathrm{~N}$ polymorphism $(\mathrm{H} 133 \mathrm{~N}$ in the LRR fragment). Therefore, the monomers are predicted to overlay one another but be offset by 79-112 residues. It should be noted that $\mathrm{C} 215$ would be close to one of the two intrinsically unstructured regions predicted. Also note in this structure the 10 of the 15 negatively charged residues $(D+E)$ are predicted to be paired with 10 of the 22 positively charged residues $(R+$ $\mathrm{K})$ which causes the pI of the homodimer formed from the LRR domain expressed in E. coli to be nearly neutral (data not shown) rather than the pI 9 measured for the monomer $[8,28]$. In contrast there was no cross-linking with Gm08-RLK1 or the protein free controls

GmRLK18-1 contained intrinsically unstructured elements Circular dichroism spectroscopy of the refolded protein from the LRR domain was used to ensure the expressed proteins had refolded adequately. In fact the spectra showed most of the proteins were well folded but with spectra characteristic of interrupting and unstructured regions within the LRR domain(s) (Figure 3) [29]. CD showed a mixed secondary structure content (40\% helix, $30 \%$ strand and turns). Interestingly, 21 percent of the LRR protein was predicted unordered or unstructured [6]. The unstructured regions intervene splitting the LRR domain in two. The intervening regions may underlie the difficulty in maintaining LRR solubility in vitro and alter the migration pattern during electrophoresis in non-denaturing gels.

\section{CLE peptide ligand binding by the LRR domain}

The affinity of binding for two LRR domain proteins, GmRLK18-1 and GmRLK08-1 was measured with a set of 5 consensus motif peptides (Table 1) found among the CLE gene family expressed in soybean roots [30]. In addition, one CLE domain found in nematode secretions was tested. As a control the peptide used to raise the anti-RLK18 antibody was tested in the same assay. It 


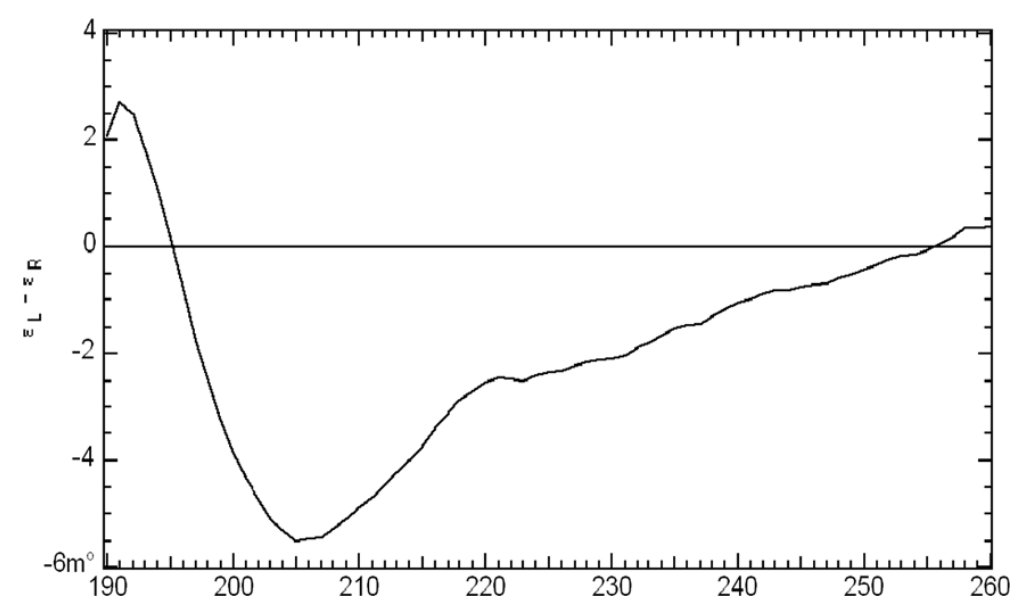

Figure 3 Circular dichroism of GmRLK18-1-LRR in 20 mM phosphate buffer pH 6.0. The CD data was processed using an integrated software package termed CDTOOL. The CD profile of GmRLK18-1 LRR is intermediary to LRRs with complete secondary structure (PGIP from Phaseolus vulgaris) and spectra generated from intrinsically unstructured proteins.

contained an LRR repeat unique to the GmRLK18-1 class of proteins. There were 6 separate motifs among the eight GmCLE peptides as 3 of the motifs were present in short (12 residues) or long peptides (28-32 residues) in the plant secretome. The GmRLK18-1-LRR had highest affinity for short peptides in general (14-45 $\mathrm{nM}$ ) and longer peptides were $2-3$ fold less strongly bound. Peptides GmCLE34 (14 nM) and T (20 nM) were bound most strongly followed by CLV3 and its nematode ortholog $\mathrm{N}$ (29-30 nM). These binding constants were within physiological ranges and suggest the LRR domain can bind multiple peptide ligands. Each of the ligands was found in vivo as part of a signal cascade that alters plant development [25-27,29,31]. In contrast, to the set of peptides associated with developmental controls, the peptides involved in the control of nodule symbiosis GmRIC1 and GmNIC1 (2, 2L and 30) were bound weakly by the GmRLK18-1 derived LRR peptide.

The GmRLK08-1 LRR domain (from the RLK protein at Rhg4) showed a lower affinity for most of the CLE peptides tested (50-338 $\mathrm{nM})$. However, the long and short versions of GmCLE34 and short version of GmCLV3 bound with the highest affinity (50-52 nM) suggesting these were among the ligand signals integrated by GmRLK08-1. The nematode peptide HgCLV3 was bound weakly $(78 \mathrm{nM})$. This result would agree with the conclusion that GmRLK08-1 protein was not the sole element underlying the resistance reaction encoded at the Rhg4 locus [9]. The GmRLK08-1 LRR domain protein bound very weakly to the symbiosis associated GmRIC and GmNIC, as did GmRLK18-1. Unlike GmRLK18-1 the GmRLK08-1 protein bound weakly to

Table 1 Sequences of CLE like peptides and control peptides used in binding assays

\begin{tabular}{|c|c|c|c|c|}
\hline \multirow[b]{2}{*}{ Sequence } & \multirow[b]{2}{*}{ Name } & \multirow[b]{2}{*}{ Synonyms } & \multicolumn{2}{|c|}{$\mathrm{Kd}(\mathrm{nM})$} \\
\hline & & & RHG1 & RHG4 \\
\hline$\underline{\text { RLAPGGPDPQHN }}$ & 2 & GmNICI, LjCLE-R2 and d LjCLE-R1 & 45 & 96 \\
\hline DLPLAPADRLAGGPDPQHNVRAPPRKP & $2 \mathrm{~L}$ & GmNICI, LjCLE-R2 and d LjCLE-R1 & 142 & 338 \\
\hline$\underline{\text { RLAPEGPDPHHN }}$ & 30 & GmCLE30, GmRICl & 44 & 84 \\
\hline AHEVPSGPNPISNR & T & GmTDIF, ZeTDIF & 20 & 204 \\
\hline SKRRVPNGPDPIHNR & 36 & GmCLE34, AtCLE36, MtCLE36 & 14 & 52 \\
\hline RAELDFNYMSKRRVPNGPDPIHNRRAGNSGR & $36 \mathrm{~L}$ & GmCLE34, AtCLE36, MtCLE36 & 49 & 51 \\
\hline$\underline{\text { RTVPSGPDPLHH }}$ & 3 & GmCLE3, AtCLE3, AtClv3 unmodified & 29 & 50 \\
\hline KGLGLHEEELRTVPSGPDPLHHHVNPPRQPR & $3 \mathrm{~L}$ & GmCLE3, AtCLE3, AtClv3 unmodified & 65 & 142 \\
\hline KRLSPSGPDPHHH & $\mathrm{N}$ & HgCLV3 & 30 & 78 \\
\hline CTLSRLKTLDISNNALNGNLPATLSNLS & L & GmLRR, GmRLK18-1 & 36 & 135 \\
\hline
\end{tabular}

Consensus sequences within the peptides were underlined. Dashed underline was the LRR peptide fragment used to estimate the Kd of dimerization and to raise the anti-Gm18RLK-1 antibody. Complete annotations can be found in [30]. Binding constants were calculated from titration experiments. 
GmTDIF. Therefore, the LRRs showed distinct peptide ligand specificities reflecting their different sequence and structures.

Estimates of the $\mathrm{Kd}$ for LRR domain dimerization could be made from the peptide $\mathrm{L}$ which contained one LRR motif. The apparent Kd for dimerization of $36 \mathrm{nM}$ for this region would suggest the whole domain homodimerization constant be less than that. In vitro both proteins extracted from roots and LRR domain peptides solubilized from E. coli showed evidence that about half the proteins existed as monomers and about half as homo-dimers (Figure 2). This equilibrium is maintained across a wide range of concentrations of protein and salt. It will be of interest in future to see if ligand binding can alter this equilibrium.

\section{Whole protein ligand binding by the LRR in Far Western analyses}

Far Western analyses of total root proteins separated on $2 \mathrm{D}$ gels showed a single interacting partner was detected that was different at 10 and 42 dai with SCN (Figure 4). At 10 dai (24 dap) the feeding site has just developed and the resistance reaction has begun. The only protein avidly bound to the LRR at this stage was a cyclophilin, with $24 \%$ identical peptide matches to 2 regions of gi 17981611 (gb AAL51087.1), with Score of 284 and Expect value of $1 \mathrm{e}^{-75}$. The cyclophilin protein was 182 amino acids long and was found on the gel as expected from DNA derived amino-acid sequence prediction at 19,392 $\mathrm{d}$ and pI 8.38 (Figure 4). The abundance of the protein spot did not change either in response to $\mathrm{SCN}$ inoculation, $F$. virguliforme inoculation or plant genotype here or in earlier studies [31].

By 28 dai (42 dap) cysts were mature (susceptible lines) or mostly dead (resistant lines). The protein binding most strongly to the LRR domain was a secreted methionine synthase from soybean. The methionine synthase protein (gi: 33325957 ) at $84.2 \mathrm{KDa}$ and $\mathrm{pI} 5.93$ was the strongest interacting partner (Figure 5). The abundance of the protein spot did not change either in response to $\mathrm{SCN}$ inoculation, $F$. virguliforme inoculation or plant genotype here or at 10 dai [31].

Proteins that contained CLE motifs were not detected at either time point (10 or 42 dai). The CLV3 like proteins in soybean range in size from 3,329-15,332 $\mathrm{d}$ and pI 5.4-11.9 but the active peptide ligands are much smaller (12-30 amino-acids), not abundant and so would not be present on the $2 \mathrm{D}$ gels.

\section{Discussion}

Shown here were the structures and abundances of proteins that interact with the LRR of GmRLK18-1[28,31]. In addition distances between homodimer subunits were mapped and measured with established techniques $[32,33]$. These experimental data will be compared with models [34-42] based on homologies in this Discussion.

\section{Structure and function}

The LRR domain of GmRLK18-1 was shown to tend towards homo-dimerization or ligand binding with equal

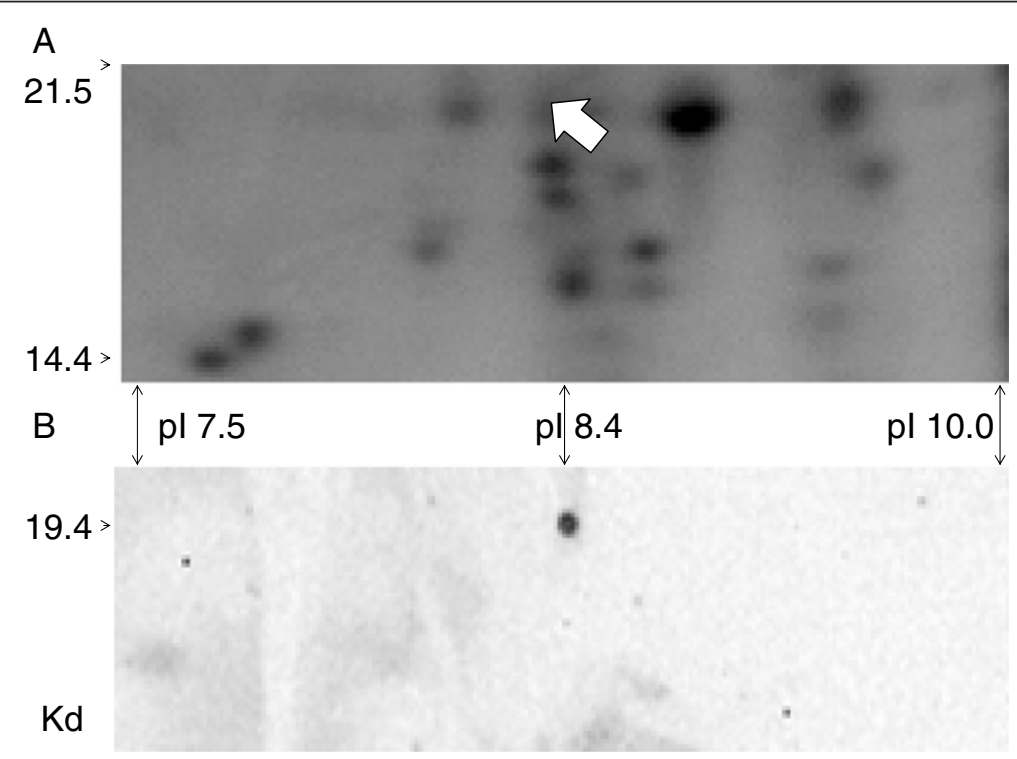

Figure 4 Far-Western analysis of soybean root proteins at 24 dap (10 dai) probed with the LRR domain of GmRLK18-1. Panel (A): Shown is a portion of a 2D gel (14.4-21.5 KDa; 7.5-10.0 pl) from 34-23 (resistant) SCN inoculated total root proteins with spots visualized with silver staining. Panel (B): Proteins transferred to a membrane and probed with purified GmRLK18-1 LRR domain and 6X his-RHG1. Anti-His-HRP was used as the secondary probe. The single spot identified (arrowed) was excised from the duplicate gel and analyzed by Q-TOF (MS-MS) to identify a cyclophilin as a GmRLK18-1 LRR domain interacting partner. 


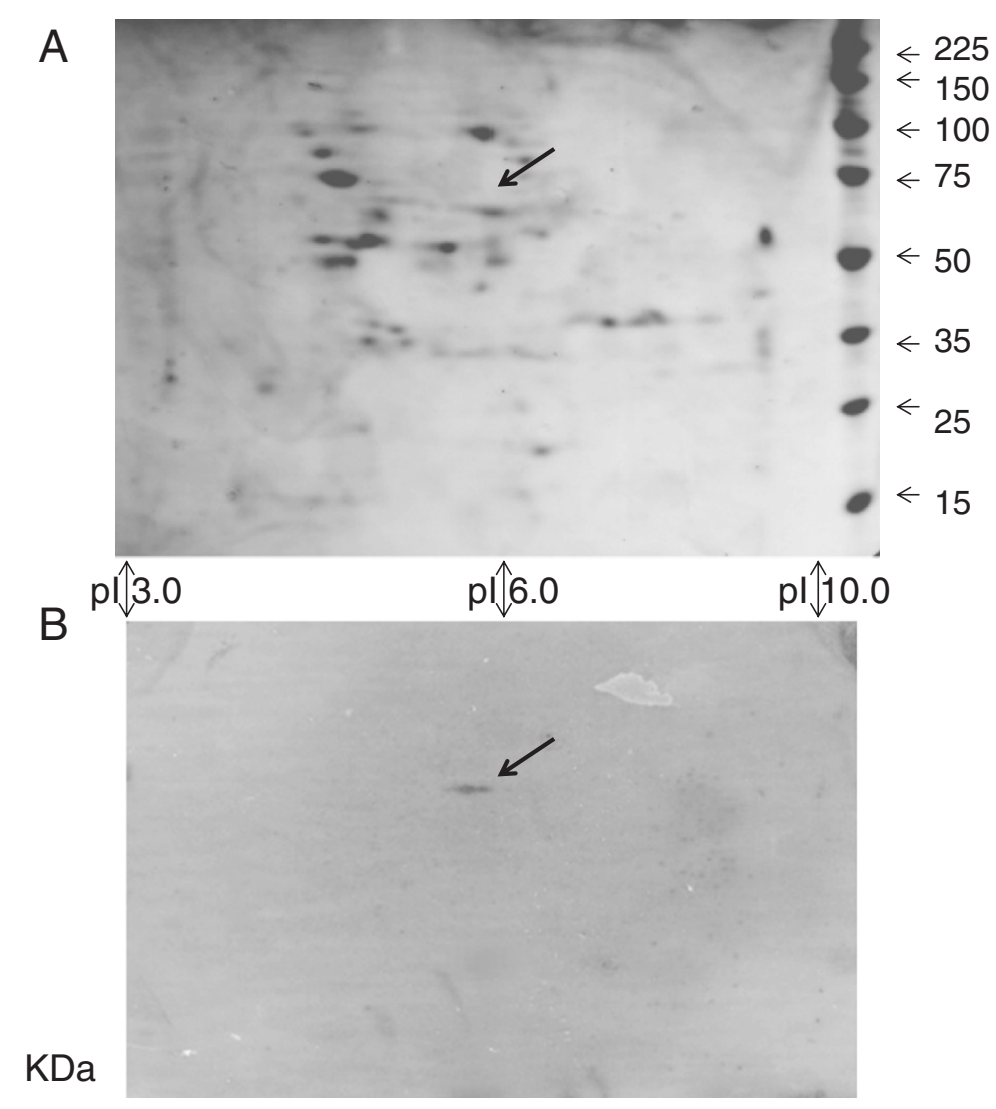

Figure 5 Far-Western analysis of soybean root proteins at 42 dap (28 dai) probed with the LRR domain of GmRLK18-1. Panel (A): Shown is a whole 2D gel (6.5-116.0 KDa; 3.0-10.0 pl) from 34-23 (resistant) SCN inoculated total root proteins with spots visualized with silver staining. Panel (B): Proteins transferred to a membrane and probed with purified GmRLK18-1 LRR domain and 6X his-RHG1. Anti-His-HRP was used as the secondary probe. The single spot identified (arrowed) was excised from the duplicate gel and analyzed by Q-TOF (MS-MS) to identify methionine synthase (Gl: 33325957) at 84.2 KDa and pl 5.93 as a GmRLK18-1 LRR domain interacting partner. The other 3 proteins were of higher abundance and so not likely to be specific interactions.

avidity. Unstructured regions were detected within it. More than 30 percent of human proteins have unstructured regions within them [42]. Unstructured proteins offer advantages over globular/fixed proteins by potentiating low affinity transient interactions with a number of targets (lack of structure allows degeneracy) [43]. It is likely that the binding of interacting partners or pathogen effectors dictate RHG LRR domain structure. Many examples in cell cycle regulation, transcriptional regulation and cell signaling involve unstructured proteins. These include BRI1 $[29,31]$ zinc-fingers, the ACTR cofactor in tumor development and the P53 involved in cell-cycle control [44]. Unlike structured proteins, most unstructured proteins have low affinities for their partners [42,45-47]. This may provide plasticity in cells needing a swift response to external or internal stimuli.

\section{Peptide ligand binding and phenotypic effects}

CLE-like protein derived consensus peptides are defined set of peptides found in plant genomes and involved in both short and long distance signaling [26,30,48-51]. Five of the 16 consensus motifs found among CLE peptides are expressed in roots (Table1), as was the GmRLK18-1. The GmRLK18-1 LRR domain had a strong binding constant for GmCLV3 and $\mathrm{N}$ that are thought to be involved in meristem differentiation [25]. During SCN pathogenesis a new meristem is initiated to bring a tracheary element close to the feeding site, $\mathrm{N}$ might mediate that and be detected by the resistance protein GmRLK18-1. $T$ is the tracheary element differentiation inhibitory factor (GmTDIF) that might provide inhibition of feeding site induced developmental processes during defence. GmCLE34 peptides were produced in pro-vascular tissues [48]. CLE domains thought to be involved in symbiosis [26] were not strongly bound suggesting they were not ligands of physiological relevance, although nematode parasitism does decrease nodulation [8].

In order to determine whether CLE peptide binding would have an effect in planta twelve plants were used 
for a root dip assay. SCN susceptible plants that had been infested with HgType 0 (isolate JB3) were depotted at 10 dai and a $0.5 \mathrm{~g}$ root sample taken. Roots were then dipped in CLE peptide TGIF or HgCLE in water at 50 pM concentration and returned to the infested soil. Immediate wilt was observed among the plants dipped in CLE peptides but not the water controls (Additional file 1: Figure S1). Wilting and stem bending was more severe in X5 (panel A-D) plants that Westag 97 (panel E-H) plants. Within one hour of dipping in CLE peptide stem bending was observed (panel B and F) and maintained, though compensated for with an S bend in X5 plants, until roots were harvested at 28 dai (panel D). The roots were harvested 18 days after CLE peptide treatments and the number of cyst counted (Table 2). The plants dipped in CLE peptides showed significantly lower numbers of SCN females suggesting a resistance reaction had been induced.

\section{Protein ligand binding}

The cyclophilin detected (Figure 4) was one of thirty encoded in the soybean genome suggesting it was a specific RHG1/RFS2 interacting partner. A role in pathogenesis for cyclophilins would be in agreement with [51]. The roles of cyclophilins include small molecule binding and receptor interactions [52]. The cyclophilin may induce a structural change in the LRRdomain probably by peptidyl-prolyl cis-trans isomerase activity (confirmation by NMR will be attempted in future experiments).

In a second Far Western analysis using older roots (42 day) later in the infection process (28 day) an S-adenosyl -L-methionine synthase was detected (Figure 5). Methionine synthase is increased in abundance and found in the secretome during fungal pathogenesis of plants [53]. Methionine synthase has a well-defined role in defense as a provider of a supply of methyl units. Recent

Table 2 Association of CLE treatments with resistance to SCN JB3 and mean root growth in non-transgenic lines

\begin{tabular}{llllll}
\hline & & Root & Root mass & \multicolumn{2}{l}{ SCN } \\
\hline Line::gene & SCN infested & mass $(\mathrm{g})$ & Range $(\mathrm{g})$ & $\mathrm{n}$ & $\mathrm{FI}(\%)$ \\
X5 & No & 1.05 & $0.81-1.44$ & 15 & $0 \pm 0.0$ \\
X5 & Yes & 0.98 & $0.73-1.31$ & 15 & $100 \pm 13$ \\
X5 + HgCLE & Yes & 1.42 & $0.95-1.81$ & 5 & $15 \pm 6$ \\
X5 + TDIF & Yes & 1.40 & $0.92-1.78$ & 5 & $8 \pm 3$ \\
Westag97 & Yes & 4.2 & $3.5-4.8$ & 5 & $120 \pm 13$ \\
Westag97 + HgCLE & Yes & 3.14 & $2.66-3.53$ & 4 & $10 \pm 3$ \\
Westag97 + TDIF & Yes & 3.10 & $2.65-3.51$ & 4 & $5 \pm 3$ \\
\hline
\end{tabular}

SCN female index in greenhouse grown seedlings at 28 days after SCN infestations. Pots were watered daily with $100 \mathrm{ml}$. Female index (FI) was the mean percentage of cysts of $\mathrm{Hg}$ Type 0 found on five plants per repetition compared to a susceptible genotype Essex. Plant treated with CLE peptides received $50 \mathrm{pM}$ dip treatments with $\mathrm{HgCLE}$ or GmTDIF. experiments have shown that during infection of diploid wheat (Triticum monococcum) by the fungus Blumaria graminis $\mathrm{f}$. sp. tritici there was a rapid synthesis of 12 proteins that are involved in the pathways of biosynthesis and supply of methyl units to lignol biosynthesis [54]. Methionine synthase was one of the genes shown to be highly induced at an early phase of infection in the epidermis. The expression was linked to host cell wall apposition formation and suggested that the pathways for synthesis of methyl units are transcriptionally activated and that this activation was for the host defense response. Cell wall appositions form during the late stages of the $\mathrm{SCN}$ resistance reaction in G. $\max$ [4-10]. Another possible role for methylation is that arginines in the LRR may be methylated during pathogen responses. Alternately it may be indirectly linked to developmental control during pathogenesis by altering the site and amount of ethylene production [52].

\section{GmRLK18-1 models}

To understand structure-function details for GmRLK181 , a three dimensional structural model was constructed. The generated model employed homology as well as $a b$ initio predictions. The model endeavors were difficult as the most suitable tertiary structure homolog had low homology to GmRLK18-1. Consequently ab initio modeling was used in the final structural prediction. PRI $[23,39]$ was used as the template structure (2bnh) from among the top hits generated by the $3 \mathrm{D}$ jury server. PRI was a 450 residue leucine rich repeat protein with a molecular weight of $49 \mathrm{kDa}$. The protein interacts and forms tight complexes with certain ribonucleases. Structure prediction was based on algorithms which select near-native conformations on the basis of discriminatory scoring functions. The models were first generated at 4-6 $\AA$ RMSD using the amino terminus domain of GmRLK18-1 (amino acids 52-440), which encompassed the LRR structural motif. In SCOP database the LRR domain (of both plants and all LRRs) was divided into 3 super families; (1) PRI-like (regular structure consisting the beta-alpha repeat); (2) L-domain like (less regular); and (3) both outer-arm dynein light chain-like and PGIPlike (beta-beta-alpha superhelix). GmRLK18-1 was predicted to be both PRI-like and PGIP-like. Several knowledge-based scoring functions have been developed with varying degrees of success $[40,41]$. These functions usually compile statistics from databases that contain experimentally determined structures, and use such statistics to test the probability of a given conformation to be native-like. Proteins of intermediate structure between two super-families often confound the programs.

\section{Model validation}

ProcheckTM analysis of the LRR domain of GmRLK181 showed that most stereochemical parameters fell 
within accepted values for structures with resolution of $2.3 \AA$ (Additional file 2: Table S1). As a resolution value cannot be assigned to the predicted structure of GmRLK18-1, the values are for comparison purposes only. Ramachandran plots for the model showed approximately 71 percent of residues in most favored regions and 26 percent of residues in allowed regions. Less than 1 percent (3) of the residues were in disallowed regions on the Ramachandran plot (Additional file 3: Figure S2, Additional file 4: Table S2).

The PROCHECK analyses of the crystal structure of PRI (Additional file 3: Figure S3) showed approximately 80 percent of the residues were in the most favorable regions and 20 percent in additionally favorable regions. Therefore, about $10 \%$ of most favored residues present in the template were lost during GmRLK18-1 model generation.

The model suggested that the LRR domain of GmRLK18-1 (Figure 6) adopts a horse-shoe type architecture similar to the crystal structure of PRI and unlike the solenoid structure of monomeric BRI1 [18,19]. In both the template and modeled protein, the long $\beta$ sheets are parallel to the helices present on the inner circumference of the proteins. In GmRLK18-1, the helices and sheets were joined by loops. Further, the $\mathrm{N}$ and $\mathrm{C}$ terminal helices were longer and the shorter helices were evenly spaced in the repeats (Figure 6).

The lack of motif conservation in known LRR domains [2] suggested that LRRs involved in pathogen recognition have a greater need to adapt to the constantly changing pathogen population. Some structural elements mainly helices, present in the template PRI structure [39] were missing in the GmRLK18-1-LRR protein (Figure 6). Surprisingly the loss of helical contact seems to be at odd numbered helical turns in the solenoid protein (helix numbers 5, 7, 911 and 13).

\section{GmRLK18-1 LRR modeled as a crystal homo-dimer}

Native PAGE of GmRLK18-1 showed a monomer as well as a homo-dimer band (Figure $2 \mathrm{~A}$ and $2 \mathrm{~B}$ ). Therefore, the GmRLK18-1-LRR protein was modeled as a crystal homo-dimer (Figure 6). This modeling was based on either the crystal dimer from decorin template [21] or an amino-peptidase or the RI dimer complexed with angiogenin (1a4y) [23]. The model developed based on the RI dimer agreed with the experimental evidence from MTBS cross-linking and was shown in Figure 6. The models based on decorin and the amino-peptidase did not agree with experimental data and was rejected. Briefly, from cross-linking from C57 two biotinylated, trypsin digest derived, two peptides from one region of a homo-dimer resulted from cross-linking. This means that C57 in the LRR or C215 in the whole protein were adjacent $(<11 \mathrm{~A})$ to the region containing the $\mathrm{H} 274 \mathrm{~N}$ polymorphism (H133N in the LRR fragment). Therefore, the monomers are predicted to overlay one another but be offset by $79-112$ residues. It should be noted that C215 would be close to one of the two intrinsically unstructured regions predicted. Also note in this structure the 10 of the 15 negatively charged residues $(D+E)$ are predicted to be paired with 10 of the 22 positively charged residues $(\mathrm{R}+\mathrm{K})$. That would cause the $\mathrm{pI}$ of the homodimer formed from the LRR domain expressed in E. coli to be nearly neutral. Neutral proteins have been detected in non-denaturing $\mathrm{pI}$ measurements using the DIABLA assay systems (data not shown) [28] rather than the pI 9 measured for the monomer (Figure 2) [8].

XA21, one of the closest homologs of the GmRLK18-1 -LRR was believed to function via homo-dimer formation $[11,24]$. Other LRRs implicated in development have also been reported to homo-dimerize. For instance, an in vivo study of the Arabidopsis Somatic Embryogenesis Receptor Kinase (SERK) showed evidence of a SERK homo-dimer whilst CLV1 LRR domain heterodimerizes with CLV2 LRR domain (25].

To evaluate stability of the mutant structures, the pseudo energy was calculated using RAPDF. The RAPDF scores suggest that all 3 mutations may affect the stability of the dimeric protein (Additional file 5: Table S3), though 2 these 3 residues were absent from the LRR fragment expressed in E. coli.

\section{Halplotype and allotype analysis of GmRLK18-1}

Previously a perfect association between allele 1 (Forrest based resistance) and resistance to the $\mathrm{SCN}$ (Hg Type 0 or race 3) was shown in three segregating populations and an association study of unrelated PIs [5]. Recently, previously susceptible plants transgenic with the Forrest allele of GmRLK18-1 were found to be resistant to both SCN and SDS [8]. Based on multiple sequence alignment of predicted GmRLK18-1 haplotypes, a quantitative trait nucleotide in the LRR of $r h g 1$ was inferred, that alters A87 to V87 in the context of Q115 and H274 rather than K115 and N274 (Additional file 6: Figure S3). There is a closely linked copy number variation that may also contribute to resistance [8].

Effects of the non synonymous point mutations on the RLK extracellular domain protein monomer stability was analyzed using the Fold X algorithm (http://fold-x.emblheidelberg.de) [46]. Of the 3 mutations that could discriminate between resistant and susceptible $r h g 1$ alleles, the A to $\mathrm{V}$ substitution at amino acid 87 was predicted to make the most significant change to the free energy of folding (Additional file 7: Table S4). The changes Q to $\mathrm{K}$ at position 115 and $\mathrm{H}$ to $\mathrm{N}$ at position 274 have an opposite effect on protein stability. However, the predicted absolute folding free energy values are not usually accurate compared to proteins with determined structures. Hence the absolute values were of little significance and only the values 


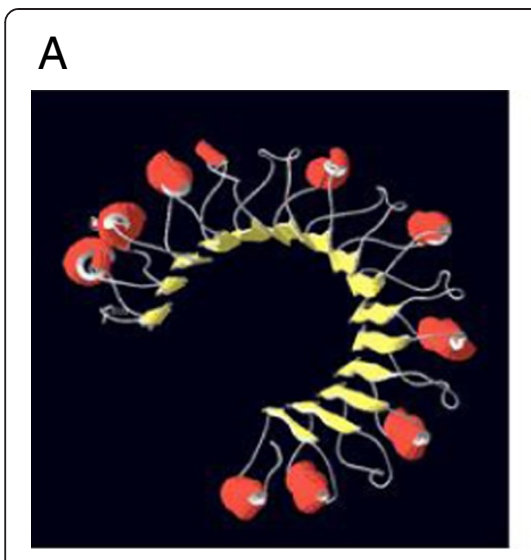

$\mathrm{E}$
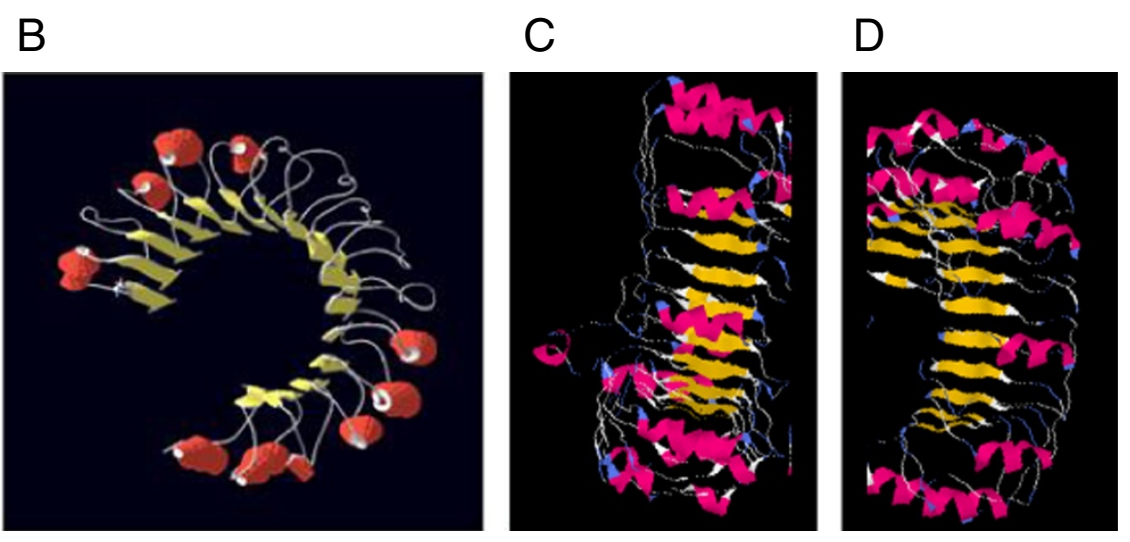

$\mathrm{F}$
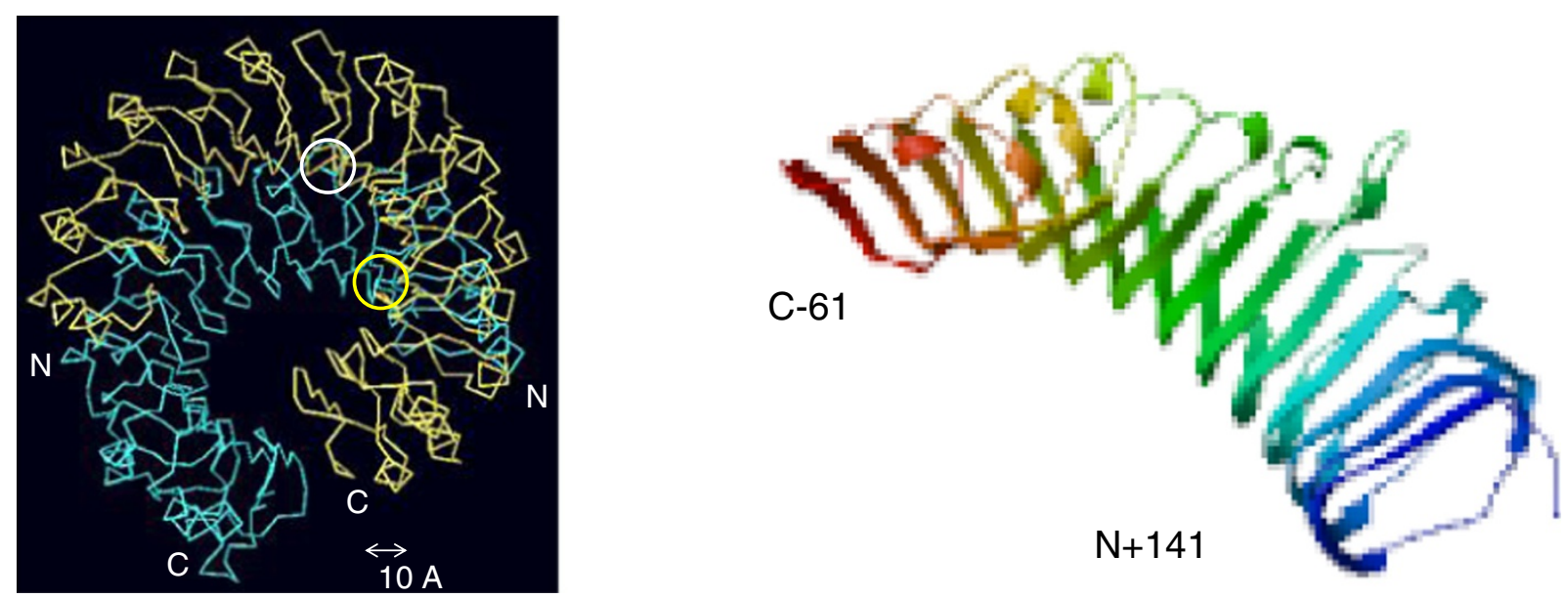

Figure 6 Predicted structures of the GmRLK18-1 LRR monomer. Panels (A-D) The $\beta$ sheet regions are shown in yellow and helical regions in red. The modeling results suggest LRRs of GmRLK18-1 at Rhg1/Rfs2 (panel A) and GmRLK8-1 at Rhg4 adopt horse shoe type architectures. In GmRLK18-1, the N and C terminal helices are longer and the shorter helices are evenly spaced in the repeats. Also seen are 4 pockets in the protein where helices do not form and the unstructured regions are the two nearest the C terminus. In GmRLK18-1 prediction, the N and C terminal helices are longer and the shorter helices are evenly spaced in the repeats whereas in the GmRLK8-1 prediction, the helices are unevenly spaced and are present only at the N or C terminal. Panel C shows the predicted GmRLK18-1 structure looking at the concave surface and panel D was looking at the convex surface. Panel (E) GmRLK18-1 was modeled as a crystal homo-dimer based on the RI template. The homo-dimer interface was held together by anti parallel $\beta$ sheets involving many residues from each monomeric chain. Chains were offset by about 90 residues. Circled in white is the cysteine less than $11 \mathrm{~A}$ from the partnering homo-dimer chain as detected by cross-linking, circled in yellow is the cysteine not near the dimer interface. (E) The predicted structure by SWISS-PROT [49] for only the LRR domain from amino acid 141-435 of GmRLK18-1 that was expressed in E. coli. The N-terminus lacked the signaling peptide. The C terminus was 61 amino acids (-61) short of the start of the trans-membrane domain.

obtained from free energy differences between the $3 \mathrm{mu}-$ tants and the wild type structure were used for relative comparisons. Functionally important residues in the GmRLK18-1-LRR were also distinguished from structural residues using a recently developed algorithm [47]. Each residue in the GmRLK18-1 LRR protein was analyzed on the basis of (a) a sequence conservation score based on multiple sequence protein alignment and (b) the free energy difference between the naturally occurring residue and the potentially optimal residue at that position. The analysis showed that the alanine residue at position 87 was the optimal residue in addition to the naturally occurring residue in the Peking cultivar. Both these results suggest that alanine 87 may be involved in providing stability to the protein. The remaining 2 amino acid substitutions may have an effect on the stability of the protein dimer.

\section{Conclusions}

This report describes a functional analysis and structural prediction of the LRR domain from a RLK protein involved in plant pest and disease resistance. Structural predictions were made and validated. The results showed that the isolated LRR of GmRLK18-1 binds peptides found in both nematode and plant secretions with 
high affinity. A question might arise over whether isolated LRRs behave in the same way as in whole RLKs and RPKs. However, the LRR was previously shown to form an active structure by CD [27]. Homo-dimerization was detected in 3 different assays (2 in vitro) and the avidity estimated by a peptide binding assay. Larger proteins were also shown to bind the LRR domain including cyclophilin, methionine synthase and a protein of the same mass and charge as the RLK monomer. Therefore, the isolate LRR behaved in ways similar to the RLK. The LRR domain was large and appeared to be binding different ligands. The RLK might integrate those signals into a single appropriate response.

The predicted structure of the RLK contrasted with the template PRI or monomeric BRI1 in a number of ways. First, the predicted model lacks some of the successive alpha helical regions present in PRI and BRI1. This may account for the unstructured content that was determined by circular dichroism spectroscopy. Secondly, it was predicted that the $\mathrm{N}$ terminal helical repeats were longer whereas the internal helical regions were evenly placed throughout the protein. In most other aspects, the model was very similar to the PRI template. Future predictions may be based on plant RLK homo-dimers of similar lengths if any structures become available or if the GmRLK18-1 homo-dimer can be crystallized. In the absence of that the prediction employed here can be used for extensive structure refinement by further cross-linking experiments.

Some important features of the candidate GmRLK18-1 protein were predicted and validated. The three polymorphisms to the C-terminal side, A87V, Q115K, and $\mathrm{H} 274 \mathrm{~N}$ may affect protein stability. The quantitative trait nucleotide underlying $\mathrm{H} 274 \mathrm{~N}$ that differentiates the Peking allotype (for resistance) from all others may have structural or functional significance. That amino acid polymorphism, $\mathrm{H} 274 \mathrm{~N}$, may play an important role in the stability of the monomer as well as the homo-dimer. Future experiments will involve mutation of this amino acid and correlating it with GmRLK18-1 stability and/or function in binding the CLE like peptide motifs found in all plants and their many of their pathogens [30].

\section{Methods}

\section{Plant materials}

Cultivars 'Essex' and 'Forrest', derived near isogenic lines 'EF34-3' and 'EF34-33', 'X5' and 'X5 transgenic with the Gm18-1 RLK' (X5::RLK) were grown in a growth chamber at $26 \mathrm{C}$ as described previously $[6,7,31]$.

\section{SCN inoculations}

Soybean plants were grown in 51 buckets, each containing 20 cones in a randomized block. Each bucket contained a 1:1 ratio of sand soil mix. The containers were placed in a water bath set at $26^{\circ} \mathrm{C}$ in the SIUC greenhouse. Growth conditions were a $14 \mathrm{~h}$ light cycle, aerial day time temperature of $30^{\circ} \mathrm{C}$ and a nighttime temperature of $22^{\circ} \mathrm{C}$. Infections were with an $\mathrm{Hg}$ Type 0 $\mathrm{SCN}$ population (JB3). Inoculated were 2,000 eggs to each 14 day old seedling. Inoculated soybean plants were removed from the cones; at 10 dai (24 dap) and roots sample of $0.5 \mathrm{~g}$ frozen or at 28 dai (42 dap) and roots frozen after cyst numbers counted. Experiments were repeated. Some experiments used a growth chamber for assays of $\mathrm{SCN}$ and root growth. The conditions varied from the greenhouse as follows. The whole chamber was set at $26^{\circ} \mathrm{C}$. The humidity was maintained at approximately 40-50\% judged by indicator cards.

\section{GmRLK18-1 and GmRLK08-1 LRR domain expression in $E$. coli}

The GmRLK18-1-LRR was expressed and purified from pET30a in E. coli as reported previously [6]. The RHG4LRR was cloned and expressed by the same methods during this work in pET28a. Briefly, the LRR residues from 141-435 (Figure 1) were expressed in E. coli strain BL21 from an IPTG inducible promoter at $10 \mathrm{C}$. The LRR proteins were isolated by precipitation of inclusion bodies and washing with extraction buffer. Pure inclusion bodies were partly solubilized by incubation in $2 \mathrm{M}$ urea and $10 \%(\mathrm{w} / \mathrm{v})$ glycerol. Folded proteins were selectively solubilized by this low concentration of urea. Proteins were further purified using immobilized metal ion affinity chromatography (IMAC) with Ni-NTA agarose. Proteins were aliquoted and stored at -20 or $-80 \mathrm{C}$ until use.

\section{Circular dichroism spectroscopy and determination of unstructured regions}

CD spectroscopy of purified GmRLK18-1 was carried out as reported previously [6]. Briefly, to remove the urea proteins were dialyzed against $0.5 \mathrm{M}$ urea, $5 \mathrm{mM}$ reduced and $2 \mathrm{mM}$ oxidized glutathione and 2.0M arginine. The protein was further dialyzed against $1.0 \mathrm{M}$ arginine, glutathione couple before dialysis against, $\mathrm{pH}$ 6.0, buffered sodium phosphate. Proteins had to be used within $48 \mathrm{~h}$ to avoid precipitation once they were urea free.

CD spectra were measured in a quartz $0.5 \mathrm{~mm}$ path length cuvette at $25^{\circ} \mathrm{C}$ for protein concentrations of $0.2-$ $0.3 \mathrm{mg} / \mathrm{ml}$. An Aviv 62-DS spectrometer (Lakewood, NJ) was used for the analysis of native, partially folded and unfolded proteins. The protein far-UV spectra were recorded over a wavelength range of 190-250nm at an averaging time of $1 \mathrm{~s}$ and 3 scans averaged over the far UV wavelength range. The CD data was processed using an integrated software package termed CDTOOL. Secondary structure content was determined with CDSSTR at the dichroweb server (http://dichroweb.cryst.bbk.ac. 
uk/html/home.shtml). The Prelink ${ }^{\mathrm{TM}}$ prediction algorithm [29] was used to probe the LRR domain for potential unstructured regions.

\section{Native PAGE to detect monomers and dimers}

The $12 \%(\mathrm{w} / \mathrm{v})$ native PAGE of GmRLK18-1 was performed using protein extracts from soybean roots [31] or E. coli [6]. Bands observed on native PAGE that were inferred to be the GmRLK18-1 LRR domain monomer and homo-dimer from E. coli were eluted. The eluants were again electrophoresed under non-denaturing and denaturing conditions on $12 \%$ (w/v) SDS PAGE using established protocols [6]. Protein pIs were measured after [8] and [28].

\section{LRR domain modification protocol with the MAB reagent}

The $2 \mathrm{M}$ urea was removed from the solubilized LRR using the Sephadex G-25 size-exclusion column chromatography. The resin was initially equilibrated with an equilibration buffer (21mM Tris-Cl pH 8.0, 1mM EDTA, 0.01\% (v/v) $\mathrm{NP}-40,5 \%(\mathrm{v} / \mathrm{v})$ glycerol and $200 \mathrm{mM} \mathrm{NaCl})$ in a ratio of $1 \mathrm{~g} / 10 \mathrm{ml}$ of resin to equilibration buffer and packed into a $1 \mathrm{ml} \mathrm{BD}{ }^{\mathrm{TM}}$ syringe tubes by spinning the tubes for 5 minutes at $1,000 \mathrm{~g}$ and $4^{\circ} \mathrm{C}$. Thereafter, the protein was applied onto the packed column and centrifuged again for 5 minutes at $1,000 \mathrm{~g}$ and $4^{\circ} \mathrm{C}$. A ten-fold excess of 2-[N2-(4-azido2,3,5,6-tetrafluorobenzoyl)-N6-(6-biotinamidocaproyl)L-lysinyl]ethyl methanethiosulfonate, (MAB; Pierce Biotechnology, Rockford, IL) reagent dissolved in dimethyl formamide was used to modify $15 \mu \mathrm{g}(3.5 \mathrm{pM})$ of the LRR in the dark for $1 \mathrm{hr}$ at room temperature after [32]. The MAB bound to the free cysteine at the $\mathrm{N}$ terminus of the LRR during this step. Later, the excess reagent was removed from the reactions via Sephadex ${ }^{\mathrm{TM}}$ G-50 sizeexclusion column chromatography.

\section{UV cross-linking and label-transfer procedure}

The MAB modified LRR domain proteins (3.5 pM) were allowed to freely bind and/or dissociate from their homodimer partners by equilibrating them at $30^{\circ} \mathrm{C}$ for 30 minutes in a $12.5 \mu \mathrm{l}$ reaction containing $30 \mathrm{mM} \mathrm{NaOH}$ HEPES [pH 7.8], 60mM NaCl, $5 \mathrm{mM} \mathrm{MgCl}_{2}$, 5\% (v/v) glycerol and $0.1 \mathrm{mg} / \mathrm{ml}$ BSA. UV-irradiation (Spectroline BIO-VISION UV/white light transilluminator, $310 \mathrm{~nm}$ and $2.65 \mathrm{~mW} / \mathrm{cm}^{2}$ at a distance of $8 \mathrm{~cm}$ ) for $2 \mathrm{~min}$ caused the biotin label to covalently link to the nearest residue (< 11.1 A away) [33]. The biotin label was transferred to that residue by adding DTT to a final concentration of $100 \mathrm{mM}$ to break the disulphide bond to the cysteine.

\section{Preparation of protein for mass spectrometry and enrichment of the biotinylated peptides}

Initially, the LRR domains were digested with trypsin (dissolved in $1 \mathrm{mM} \mathrm{HCl}$ ), in a ratio of 1:5 of the enzyme: substrate, for 3 hours in $25 \mathrm{mM}$ ammonium bicarbonate at $37^{\circ} \mathrm{C}$. Then the reaction was stopped with the protease inhibitor PMSF in ( 20 fold molar excess to trypsin) before passing through a monomeric avidin column (with a binding capacity of biotinylated proteins to be $\sim 1.2 \mathrm{mg} / \mathrm{ml}$ ) which was already blocked with blocking buffer ( $4 \mathrm{mM}$ d-biotin dissolved in $1 \mathrm{x}$ PBS) and also washed with 12 column volumes of elution buffer $(0.4 \%$ (v/v) trifluoro-acetic acid and 40\% (v/v) acetonitrile). The biotinylated peptides were eluted from the column using 5 column volumes of the elution buffer $(200 \mu \mathrm{l})$. Samples were sent for peptide fragment size estimation to the MS facility at SIUC for MALDI analysis. Briefly, a $1 \mu \mathrm{l}$ drop of trypsinized protein was added to $1 \mu \mathrm{l}$ of MALDI matrix (5 $\mathrm{mg} / \mathrm{ml}$ alpha-cyano-4-hydroxycinnamic acid in $50 \%(\mathrm{v} / \mathrm{v})$ acetonitrile) and dried on a stainless steel plate. A Bruker Daltonics Microflex ${ }^{\text {TM }}$ (Billerica, MA) time of flight mass spectrometer was used to analyze the sample with a pulse nitrogen laser set at $337 \mathrm{~nm}$ with a $20 \mathrm{kHz}$ repetition rate and ions that resulted were observed in the positive ion mode as the sum of 500 individual mass spectra over an $\mathrm{m} / \mathrm{z}$ range from 1-10 thousand.

\section{Western and Far Western analysis with LRR domain probes}

SDS-PAGE of total plant proteins from Essex and Forrest followed by Western hybridization was carried out by methods described previously [6,7] with the following modifications. For the Western hybridizations, a custom made antibody generated against the peptide CTL SRL KTL DIS NNA LNG NLP ATL SNL S from the LRR domain of RHG1 was used (Alpha Diagnostics, San Antonio, Texas). As a secondary antibody, an anti rabbit IgG HRP was used (GE healthcare, Milwaukee, Wisconsin).

For Far-Westerns the LRR domain was used as a probe to filters transferred from 1 or $2 \mathrm{D}$ gels. As the secondary probe, anti-his antibody conjugated to HRP (1-10,000 dilution; Invitrogen, Carlsbad CA) was used. Spots and bands were picked manually and the proteins in them digested with trypsin and identified by direct infusion MS/ MS following the methods in [31].

\section{Ligand binding assays}

For in vitro assays potential peptide ligands were labeled with fluorescein-5-isothiocyanate (FITC) in a molar ratio of 10:1 at room temperature for 60 mins (G-Biosciences, St Louis, MO). Labeled peptides were stored at $-20 \mathrm{C}$ in $10 \%(\mathrm{v} / \mathrm{v})$ glycerol until use. For ligand binding assays peptides were diluted to $50 \mathrm{nM} / \mathrm{ml}$ in $20 \mathrm{mM}$ phosphate buffer (pH6.9) in a cuvette and the amount of polarized luminescence measured in a luminescence spectrometer scan from 500-600 nm with excitation energy of 494 $\mathrm{nm}$ and a detection wavelength $520 \mathrm{~nm}$. The excitation slit was set to $4 \mathrm{~nm}$ and the emission slit was set at 4 
$\mathrm{nm}$ with a scan speed of $100 \mathrm{~nm} / \mathrm{min}$. Ligands were added to the cuvette in excess (50 nM) Peptides were added in $5 \mathrm{nM}$ aliquots and the increase in polarization measured as fluorescence units. Base-line binding to non-CLE and non-LRR peptides was subtracted from the polarization units. Experiments were repeated 3 occasions with 3 different protein preparations. Dissociation constants (Kds) were calculated from double reciprocal Scatchard plots [31].

In planta assays used twelve plants of each of cultivar X5 and Westag 97 in two separate experiments over a month for a root dip assay [55]. SCN susceptible plants that had been infested with HgType 0 (isolate JB3) were depotted at 10 dai and a $0.5 \mathrm{~g}$ root sample taken. Roots were then dipped in CLE peptide TGIF or HgCLE in water at $50 \mathrm{pM}$ concentration and returned to the infested soil. Photographs were taken at $2 \mathrm{~min}, 5 \mathrm{~min}$ and 18 days after treatments.

\section{Bioinformatic analysis of GmRLK18-1}

The nucleotide sequence for GmRLK18-1, the RLK encoded within the rhg1 locus, was translated to its polypeptide sequence in-silico using the EXPASY translation tool (http://www.expasy.ch/tools/dna.html). The complete (855 amino acid) sequence obtained for GmRLK18-1 was analyzed for domain architecture (smart.embl-heidelberg. de). The LRR-domain (amino acid 52 to amino acid 440) was used for generation of models. The Apache server found at (supfam.mrc-lmb.cam.ac.uk/SUPERFAMILY) was used to predict the superfamily, fold and class of the protein. The ratio of synonymous to nonsynonymous substitutions was analyzed by the web based algorithm SNAP (http://www.hiv.lanl.gov/content/sequence/SNAP/SNAP.html).

\section{Comparative and homology modeling of structures}

The first model of GmRLK18-1 structure was generated using the RAMP software suite of programs (http:// compbio.washington.edu; http://protinfo.compbio.washington.edu). The initial template and the corresponding sequence alignments of GmRLK18-1 were chosen from the 3D-Jury server (http://BioInfo.PL). The best template was decided by inspection of the consensus sequence of the GmRLK18-1-LRR protein and all template sequences (Additional file 8: Figure S4). Finally, these alignments were adjusted manually to obtain the best alignment for the LRR-domain. The crystal structure of the PRI (PDB entry $2 \mathrm{BNH}$ ) was used as the template structure for modeling of GmRLK18-1.

The initial models were constructed with a minimum perturbation approach [34]. Variable side chains and main chains were constructed by using a graph-theory clique-finding approach, which explores a variety of possible conformations for the respective side chains and main chains and finds the optimal combination by using an all-atom scoring function. These approaches were described in detail previously [34-37]. Briefly, based on each individual alignment, initial models were generated by copying atomic coordinates for the main chain (excluding any insertions/loops) and for the side chains of residues that were identical in the target and template proteins. Models for residues that differed in side chain type were constructed using the SCWRL3 program. A set of possible conformations were generated for the main chain regions (loops) considered to vary in target with respect to the template structures. The models included potential insertions and deletions. Main chain sampling was performed using an exhaustive enumeration technique based on 14 discrete torsion angle states. Refinements of the ab-initio sampling protocols were also incorporated into the loop sampling technique $[35,38]$. All models were refined with ENCAD, and the best model was selected using the Residue all-atom conditional Probability Discriminatory Function (RAPDF).

The homo-dimer conformation of GmRLK18-1 was generated using the software package XtalView, according to the relative position of the homo-dimer conformation of a Ribonuclease inhibitor-angiogenin complex (1a4y). The structures of GmRLK18-1 allotypes (A87V, Q115K and H274N) were generated using SCWRL3. To evaluate the stability of the structures, their pseudo-energy was calculated using RAPDF.

\section{Structural model validation and analysis in silico}

Protein structure validation checks, mainly the stereochemical quality of protein structure were performed using PROCHECK (http://www.ebi.ac.uk/thornton-srv/ software/PROCHECK/). Analysis of main chain, side chain parameters and Ramachandran plot analysis used the PROCHECK algorithm. The 3 amino acid changes from the SCN Type I resistance allotype to the susceptible allotypes were analyzed further for functional and structural importance using two prediction servers (http://robetta. bakerlab.org/; http://fold-x.embl-heidelberg.de).

\section{Additional files}

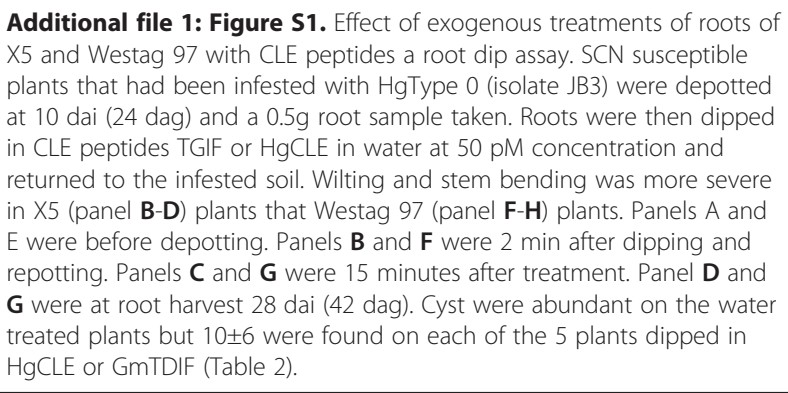

Additional file 1: Figure S1. Effect of exogenous treatments of roots of X5 and Westag 97 with CLE peptides a root dip assay. SCN susceptible plants that had been infested with HgType 0 (isolate JB3) were depotted at 10 dai (24 dag) and a $0.5 \mathrm{~g}$ root sample taken. Roots were then dipped in CLE peptides TGIF or HgCLE in water at 50 pM concentration and returned to the infested soil. Wilting and stem bending was more severe in X5 (panel B-D) plants that Westag 97 (panel F-H) plants. Panels A and G were at root harvest 28 dai (42 dag). Cyst were abundant on the water HgCLE or GmTDIF (Table 2). 
Additional file 2: Table S1. PROCHECK analysis of main chain parameters for the modeled GmRLK18-1 LRR structure. Stereochemical parameters such as percentage residues in allowed regions, omega angle standard deviation, the hydrogen bond standard deviation and the overall quality of the models are shown for the modeled GmRLK18-1-LRR and typical proteins resolved at $2.3 \AA$ resolutions.

Additional file 3: Figure S2. Ramachandran plot of homologymodeled structure of GmRLK18-1 based on porcine ribonuclease inhibitor template. Each amino acid residue is represented by a black dot. Red shows the most favored residue positions, yellow additionally allowed residue positions, beige residue generously allowed residue positions and white disallowed residue positions.

Additional file 4: Table S2. Ramachandran plot statistics for GmRLK181 calculated from PROCHECK. Approximately 71 percent of the amino acid residues within the modeled protein were in allowed regions of the Ramachandran plot. An additional 26 percent of the amino acid residues were in additional allowed regions whereas 2.4 percent of the amino acids fell in generously allowed regions of the Ramachandran plot. Less than one percent residues (3) were in disallowed regions.

Additional file 5: Table S3. RAPDF scores for 3 LRR mutants and the wild type GmRLK18-1-LRR. The RAPDF scores suggested that these mutations may affect the stability of the homodimeric protein although these residues were not directly implicated in the homodimer interface.

Additional file 6: Figure S3. Sequence diversity among the seven GmRLK18-1 allotypes. Alanine at position 87 is only present in the 'Peking' sequence. Two additional changes $\mathrm{Q}$ to $\mathrm{K}$ at position 115 and $\mathrm{H}$ to $\mathrm{N}$ at position 274 are not exclusive to resistance type I.

Additional file 7: Table S4. Effect of three non-synonymous substitutions on protein stability calculated from the Fold $X$ algorithm (http://fold-x.embl-heidelberg.de). The computed free energy of folding and the change in free energy between the wild type protein (Peking allele) and the mutant proteins is shown. The $\mathrm{H}$ to $\mathrm{N}$ and $\mathrm{Q}$ to $\mathrm{K}$ change increase the free energy of folding, whereas the alanine to valine change results in a significant decrease in the free energy.

Additional file 8: Figure S4. The $3 D$ structures of $L R R$ containing proteins showing high sequence homology to RHG1. Panel (a) shows the crystal structure of BRI1 (pdb id: 3RGX). Brassinosteroid recognition is mediated through the LRR domain of BRASSINOSTEROID-INSENSITIVE 1 (BRI1). BR1l exists as a monomer. The protein exists as a helical solenoid structure. (b) crystal structure of the Polygalacturonase inhibiting protein (PGIP). The PGIP protein (PDB id: 1ogq) is a cell wall localized protein that interacts with fungal endopolygalacturonases. (c) X-ray structure of the porcine ribonuclease inhibitor (PRI). The Leucine rich repeat of PRI (PDB id: $2 \mathrm{BNH}$ ) forms tight complexes with ribonucleases thereby regulating RNA levels. PRI adopts a horseshoe configuration with the LRR motif composed of repeat beta-loop helix units.

\section{Abbreviations}

LRR: Leucine rich repeat; RLK: Receptor like kinase; CLE: Clavata like elicitor.

\section{Authors' contributions}

DAL conceived of the study and all of the analysis. AS and JA carried out the Far Westerns. RS and JY carried out the homology modeling. SV developed the GmRLK08-1 expression vector. DAL and SK carried out the CLE binding assays. AG carried out the cross-linking experiment. DAL carried out the root dip assays. DAL drafted the manuscript. AS and JA provided critical review, interpretation of results and feedback. All authors read and approved the final manuscript.

\section{Acknowledgements}

The project was supported by the NSF under Grant No. 0487654. Any opinions, findings, and conclusions or recommendations expressed in this material are those of the author(s) and do not necessarily reflect the views of the NSF. We thank Dr. Mary Kinsel for assistance with mass spectrometry and Dr. Shehzad Khan for assistance with fluorescence anisotropy.

Afzal and Srour as joint first authors.

\section{Author details}

'Department of Molecular Biology, Microbiology and Biochemistry and Center for Excellence the Illinois Soybean Center, Southern Illinois University at Carbondale, IL 62901, USA. ²Genomics Core Facility; Department of Plant Soil and Agricultural Systems, Southern Illinois University at Carbondale, Carbondale, IL 62901-4415, USA. ${ }^{3}$ Department of Molecular Biology and Biochemistry, University of California at Irvine, Irvine, CA 92697-4560, USA. ${ }^{4}$ Department of Microbiology Box 357242, University of Washington, Seattle, WA 98195-7242, USA. ${ }^{5}$ Department of Chemistry, Southern Illinois University at Carbondale, IL 62901, USA.

Received: 3 January 2012 Accepted: 5 February 2013

Published: 15 March 2013

\section{References}

1. Jones JDG, Dangl JL: The plant immune system. Nature 2006, 444:323-329.

2. Afzal AJ, Wood AJ, Lightfoot DA: Plant receptor-like serine threonine kinases: Roles in signaling plant defense. Molec Plant Microb Interact 2008, 21:507-517.

3. Wrather JA, Koenning SR, Anderson TR: Effect of diseases on soybean yields in the United States and Ontario (1999 to 2002). Plant Health Progr 2003. doi:10.1094/PHP-2003-0325-01-RV.

4. Palmateer AJ, Schmidt ME, Stetina SR, Russin JS: Temperature effects on race determination in Heterodera glycines. J Nematol 2000, 32:349-355.

5. Ruben E, Aziz J, Afzal J, Njiti VN, Triwitayakorn K, lqbal MJ, Yaegashi S, Arelli $P R$, Town CD, Ishihara H, Meksem K, Lightfoot DA: Genomic analysis of the 'Peking' rhg1 locus: Candidate genes that underlie soybean resistance to the cyst nematode. Mol Genet Genome 2006, 276:320-330.

6. Afzal AJ, Lightfoot DA: Soybean disease resistance protein GmRLK18-1-LRR domain expressed, purified and refolded from Escherichia coli inclusion bodies: preparation for a functional analysis. Protein Expr Purif 2007, 53:346-355.

7. Afzal AJ, Srour A, Hemmati N, Saini N, Arelli P, Lightfoot DA: The multigeneic Rhg1/Rfs2 locus: A model for the effects on root development, nematode resistance recombination suppression. Theor Appl Genet 2012, 124:1027-1039.

8. Srour A, Afzal AJ, Saini N, Blahut-Beatty L, Hemmati N, Simmonds DH, El Shemy H, Town CD, Lightfoot DA SH: The receptor like kinase transgene from the Rhg1/Rfs2 locus caused pleiotropic resistances to soybean cyst nematode sudden death syndrome. BMC Genomics 2012. 13:43-53.

9. Liu X, Liu S, Jamai A, Bendahmane A, Lightfoot DA, Mitchum MG, Meksem $\mathrm{K}$ : Soybean cyst nematode resistance in soybean is independent of the Rhg4 locus LRR RLK gene. Funct Integrated Genom 2012. doi:10.1007/ s10142-011-0225-4.

10. Cook DE, Lee TG, Guo X, Melito S, Wang K, Bayless AM, Wang J, Hughes TJ, Willis DK, Clemente TE, Diers BW, Jiang J, Hudson ME, Bent AF: Copy Number Variation of Multiple Genes at Rhg1 Mediates Nematode Resistance in Soybean. Science 2012, 338:1206-1209.

11. Wang GL, Ruan DL, Song WY, Sideris S, Chen LL, Pi LY, Zhang SP, Zhang Z, Fauquet C, Gaut BS, Whalen MC, Ronald PC: Xa21D encodes a receptor-like molecule with a leucine-rich repeat domain that determines racespecific recognition is subject to adaptive evolution. Plant Cell 1998, 10:765-779.

12. Gomez-Gomez L, Boller T: Flagellin perception: a paradigm for innate immunity. Trend Plant Sci 2002, 7:251-256.

13. Kachroo A, Schopfer CR, Nasrallah ME, Nasrallah JB: Allele-specific receptorligand interactions in Brassica self-incompatibility. Science 2001, 293:1824-1826.

14. Evdokimov AG, Anderson DE, Routzahn KM, Waugh DS: Unusual molecular architecture of the Yersinia pestis cytotoxin YopM: a leucine-rich repeat protein with the shortest repeating unit. J Mol Biol 2001, 312:807-821.

15. Schubert WD, Urbanke C, Ziehm T, Beier V, Machner MP, Domann E, Wehland T, Chakraborty T, Heinz DW: Structure of internalin, a major invasion protein of Listeria monocytogenes, in complex with its human receptor E-cadherin. Cell 2002, 111:825-836.

16. Di Matteo A, Federici L, Mattei B, Salvi G, Johnson K, Savino C, De Lorenzo G, Tsernoglou D, Cervone F: The crystal structure of polygalacturonaseinhibiting protein (PGIP), a leucine-rich repeat protein involved in plant defense. Proc Natl Acad Sci USA 2003, 100:10124-10128.

17. Vinagre F, Vargas C, Schwarcz K, Cavalcante J, Nogueira EM, Baldani Jl, Ferreira PC, Hemerly AS: SHR5: a novel plant receptor kinase involved in 
plant-N2-fixing endophytic bacteria association. J Exp Bot 2006, 57:559-69.

18. Hothorn M, Belkhadir Y, Dreux M, Dabi T, Noel JP, Wilson IA, Chory J: Structural basis of steroid hormone perception by the receptor kinase BRI1. Nature 2011, 474:467-471

19. She J, Han Z, Kim TW, Wang J, Cheng W, Chang J, Shi S, Wang J, Yang M, Wang ZY, Chai J: Structural insight into brassinosteroid perception by BRI1. Nature 2011, 474:472-476.

20. Hung LH, Samudrala R: PROTINFO: secondary and tertiary protein structure prediction. Nucl Acid Res 2003, 31:3296-3299.

21. Scott PG, McEwan PA, Dodd CM, Bergmann EM, Bishop PN, Bella J: Crystal structure of the dimeric protein core of decorin, the archetypal small leucine-rich repeat proteoglycan. Proc Natl Acad Sci USA 2004, 101:15633-15638.

22. He XLL, Bazan JF, McDermott G, Park JB, Wang K, Tessier-Lavigne M, He ZG, Garcia KC: Structure of the Nogo receptor ectodomain: A recognition module implicated in myelin inhibition. Neuron 2003, 38:177-185.

23. Okamoto A, Nakai $Y$, Hayashi H, Hirotsu K, Kagamiyama K: Crystal structures of Paracoccus denitrificans aromatic amino acid aminotransferase: A substrate recognition site constructed by rearrangement of hydrogen bond network. J Mol Biol 1998, 280:443-461.

24. Han SW, Lee SW, Ronald PC: Secretion, modification and regulation of Ax21. Curr Opin Microbiol 2011, 14:62-67.

25. Replogle A, Wang J, Bleckmann A, Hussey RS, Baum TJ, Sawa S, Davis EL, Wang $X$, Simon R, Mitchum MG: Nematode CLE signaling in Arabidopsis requires CLAVATA2 and CORYNE. Plant J 2011, 65:430-440.

26. Reid DE, Ferguson BJ, Gresshoff PM: Inoculation- and nitrate-induced CLE peptides of soybean control NARK-dependent nodule formation. MPMI 2011, 24:606-618.

27. Basak J, Bahadur RP: Theoretical model of the three-dimensional structure of a disease resistance gene homolog encoding resistance protein in Vigna mungo. J Biomol Struct Dyn 2006, 24:123-130.

28. Montgomery R, Shay H, McCarroll M, Tolley L: DIABLA: A New Screening Method for the Discovery of Protein Targets. J Proteome Res 2008, 7:4594-4597.

29. Coeytaux K, Poupon A: Prediction of unfolded segments in a protein sequence based on amino acid composition. Bioinformatics 2005 21:1891-1900. Norio Matsushima N, Miyashita H Plant leucine-rich repeat (LRR) - containing proteins interrupting insertions. Biomolecules 2012. in press.

30. Oelkers K, Goffard N, Weiller GF, Gresshoff PM, Mathesius U, Frickey T: Bioinformatic analysis of the CLE signaling peptide family. BMC Plant Biol 2008, 8:1

31. Afzal AJ, Natarajan A, Saini N, lqbal MJ, Geisler MA, El Shemy H, Mungur R, Willmitzer $\mathrm{L}$, Lightfoot DA: The nematode resistance allele at the rhg1 locus alters the proteome and metabolome of soybean roots. Plant Physiol 2009, 151:1264-1280.

32. Goil A: Mapping the binding interactions between the ISW2 complex and nucleosomes. MS Thesis. IL USA: Carbondale:156.

33. Green NS, Reisler E, Houk KN: Quantitative evaluation of the lengths of homobifunctional protein cross linking reagents. Protein Sci 2001, 10:1293-1304

34. Xia $Y$, Huang ES, Levitt $M$, Samudrala R: $A b$ initio construction of protein tertiary structures using a hierarchical approach. J Molec Biol 2000, 300:171-185.

35. Samudrala R, Xia Y, Huang E, Levitt M: Ab initio protein structure prediction using a combined hierarchical approach. Prot-Struc Func Genet 1999, 7:194-198.

36. Samudrala R, Levitt M: A comprehensive analysis of 40 blind protein structure predictions. BMC Struct Biol 2002, 2:3.

37. Defay $T$, Cohen FE: Evaluation of current techniques for $a b$ initio protein structure prediction. Proteins 1995, 23:431-45

38. Liu T, Samudrala R: The effect of experimental resolution on the performance of knowledge-based discriminatory functions for protein structure selection. Protein Eng Des Selec 2006, 19:431-437.

39. Kobe B, Deisenhofer J: Mechanism of ribonuclease inhibition by ribonuclease inhibitor protein based on the crystal structure of its complex with ribonuclease A. J Mol Biol 1996, 264:1028-43.

40. Ngan SC, Inouye MT, Samudrala R: A knowledge-based scoring function based on residue triplets for protein structure prediction. Protein Eng Des Sel 2006, 19:187-93.
41. McDermott JE, Corrigan A, Peterson E, Oehmen C, Niemann G, Cambronne ED, Sharp D, Adkins JN, Samudrala R, Heffron F: Computational prediction of type III and IV secreted effectors in Gram-negative bacteria. Infect Immun 2011, 79:23-32.

42. Demarest SJ, Martinez-Yamout M, Chung J, Chen HW, Xu W, Dyson HJ, Evans RM, Wright PE: Mutual synergistic folding in recruitment of CBP/ p300 by p160 nuclear receptor co-activators. Nature 2002, 415:549-553.

43. Dunker AK, Silman I, Uversky VN, Sussman JL: Function and structure of inherently disordered proteins. Curr Opin Struct Biol 2008, 18:756-764.

44. Bowman P, Galea CA, Lacy E, Kriwacki RW: Thermodynamic characterization of interactions between p27(Kip1) activated and nonactivated Cdk2: Intrinsically unstructured proteins as thermodynamic tethers. Biochim Biophys Acta-Prot Proteom 2006, 1764:182-189.

45. Mészáros B, Simon I, Dosztányi Z: Prediction of protein binding regions in disordered proteins. PLoS Comput Biol 2009, 5:e1000376. doi:10.1371/ journal.pcbi.1000376

46. Guerois R, Nielsen JE, Serrano L: Predicting changes in the stability of protein-protein complexes: A study of more than 1,000 mutations. J Molec Biol 2002, 320:369-387.

47. Cheng G, Qian B, Samudrala R, Baker D: Improvement in protein functional site prediction by distinguishing structural functional constraints on protein family evolution using computational design. Nucl Acids Res 2005, 33:5861-5867

48. Djordjevic MA, Oakes M, Wong CE, Singh M, Bhalla P, Kusumawati L, Imin N: Border sequences of Medicago truncatula CLE36 are specifically cleaved by endoproteases common to the extracellular fluids of Medicago and soybean. J Exp Bot 2011, 62:4649-4659.

49. Arnold K, Bordoli L, Kopp J, Schwede T: The SWISS-MODEL Workspace: A web-based environment for protein structure homology modeling. Bioinformatics 2006, 22:195-201.

50. Fukuda H, Higashiyama T: Diverse functions of plant peptides: Entering a new phase. Plant Cell Physiol 2011, 52(1):1-4.

51. Coaker G, Falick A, Staskawicz B: Activation of a phytopathogenic bacterial effector protein by a eukaryotic cyclophilin. Science 2005, 308:548-550

52. Koornneef A, Pieterse CMJ: Cross talk in defense signaling. Plant Physio 2008, 146:839-844

53. Schenk PM, Kazan K, Wilson I, Anderson JP, Richmond T, Somerville SC, et al: Coordinated plant defense responses in Arabidopsis revealed by microarray analysis. Proc Natl Acad Sci USA 2000, 97:11655-11660.

54. Bhuiyan NH, Selvaraj G, Wei Y, King J: Gene expression profiling and silencing reveal that monolignol biosynthesis plays a critical role in penetration defence in wheat against powdery mildew invasion. $J$ Exp Bot 2009, 60:509-521.

55. Lightfoot DA: Resistance genes and proteins active against Fusarium root rots, cyst nematodes and soybean sudden death syndrome and methods employing same. 2012. Patent pending 61/432,226. Final filing Date 1/13/2012.

doi:10.1186/1471-2229-13-43

Cite this article as: Afzal et al:: Homo-dimerization and ligand binding by the leucine-rich repeat domain at RHG1/RFS2 underlying resistance to two soybean pathogens. BMC Plant Biology 2013 13:43.

\section{Submit your next manuscript to BioMed Central and take full advantage of:}

- Convenient online submission

- Thorough peer review

- No space constraints or color figure charges

- Immediate publication on acceptance

- Inclusion in PubMed, CAS, Scopus and Google Scholar

- Research which is freely available for redistribution 